\title{
OPTIMIZATION OF WIDE-FIELD SECOND-HARMONIC GENERATION MICROSCOPY FOR FAST IMAGING OF LARGE SAMPLE AREAS IN BIOLOGICAL TISSUES
}

\author{
A. Dementjev ${ }^{\text {a }}$, R. Rudys ${ }^{\text {b,c }}$, R. Karpicz ${ }^{\text {a }}$, and D. Rutkauskas ${ }^{a}$ \\ a Institute of Physics, Center for Physical Sciences and Technology, Savanoriu 231, 02300 Vilnius, Lithuania \\ ${ }^{\mathrm{b}}$ Department of Biomodels, State Research Institute Centre for Innovative Medicine, Santariškiu 5, 08406 Vilnius, Lithuania

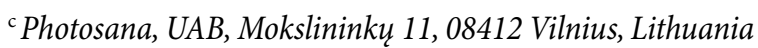 \\ Email: danielis.rutkauskas@ftmc.lt
}

Received 19 May 2020; revised 1 July 2020; accepted 1 July 2020

\begin{abstract}
Second-harmonic generation (SHG) microscopy is a label-free imaging method that can be used to visualize the detailed arrangement of collagen structures in biological tissues. Here, we sought to optimize the speed of microscopic SHG image acquisition of macroscopic fixed tissue sample areas by employing the wide-field imaging with a high power and medium, $1 \mathrm{MHz}$ pulse repetition frequency laser in combination with a mechanical sample scanning. Unlike in the conventional laser-scanning microscopy, the optimum of the wide-field acquisition entails an interplay between the size of the illuminated area and the intensity of the generated signal. We delineate quantitative procedures to set the image parameters for the maximum speed of the tiled image acquisition, and also describe the possible optimization of the laser parameters for further enhancement of the speed of acquisition.
\end{abstract}

Keywords: microscopy, second-harmonic generation, wide-field, collagen, tissue samples

PACS: 87.64.mn, 42.65.Ky, 87.14.em

\section{Introduction}

Second-harmonic generation (SHG) is a secondorder nonlinear optical process, where two photons of equal energy are scattered by the material and combined into one photon of twice the energy. Because the nonlinear susceptibility associated with this process is non-zero in ordered and non-centrosymmetric structures, $\mathrm{SH}$ is generated in anisotropic crystals, at interfaces, or where the symmetry is broken by an electric field. From biological materials, the most efficient $\mathrm{SH}$ harmonophores are collagen, myosin and microtubulin fibrils, in the order of decreasing efficiency of generation. The SHG phenomenon was demonstrated in the 1960s [1]], the possibility of its ap- plication for imaging was envisaged in the 1970s [2], and the first instance of SHG imaging of biological tissue was realized in the 1980s [3]. Since then, the SHG imaging has undergone significant development and is now one of the major techniques for the microscopic label-free visualization of such biological material as collagen fibrils/fibers in the extracellular matrix [4]. Due to the underlying physical principles, the SHG signal is highly sensitive to the particulars of the collagen structural arrangement [5]. And this is the reason SHG imaging has found its place in the biological and tissue engineering research [6] and in the study of various biomedical problems, such as cancer, fibrosis and connective tissue disorders that are associated with collagen changes [阿. 
Since SHG is the nonlinear optical process, it is most conveniently invoked by using a femtosecond laser source. The conventional way to arrange for the SHG imaging is to tightly focus the laser light into the sample with an objective, raster scan the focal volume over an area in the sample, and reconstruct an image by associating the intensity of the generated $\mathrm{SH}$ signal detected by a point detector with the position of illumination volume in the sample [8]. The rate of such an acquisition is, however, limited by the speed of laser-scanning, the efficiency of SHG in the sample, and the fact that it uses a single point detector to probe the signal intensity at different positions in the sample. A simpler, because it is scanning less and potentially faster, is the recently emerged alternative of the wide-field SHG imaging, where a relatively large sample area is illuminated at a time, and the resulting image is projected onto a two-dimensional detector, such as CCD or CMOS, thereby effectively exploiting the detection with a number of point detectors (detector pixels) in parallel [9]. There is an ongoing discussion as to the optimal conditions for the SHG imaging regarding the laser pulse repetition frequency and the corresponding laser pulse energy that translates in the illumination fluence on the sample. Roke et al. showed that using a medium pulse repetition rate of $200 \mathrm{kHz}$ in the wide-field offers a potential of higher signal throughput at lower illumination fluences compared to the laser-scanning with high or wide-field with a low pulse repetition rate [10]. On the other hand, where only very low fluences can be tolerated, such as for the imaging of muscle contractility, Barzda et al. demonstrated that it is beneficial to use a high power and high, $60 \mathrm{MHz}$ pulse repetition rate laser [11]. Here, we report on the widefield SHG imaging with yet another emphasis of fast imaging of large areas of fixed tissue samples. For that, similarly to [10], we use a medium repetition rate and relatively high pulse energy laser. We start by considering the laser parameters required for the wide-field imaging to be advantageous compared to the laser-scanning. Then, we evaluate the maximum size of the SHG image of desired intensity that can be acquired with our laser within the chosen integration time. Afterwards, we explore what the optimal image size is with the corresponding integration time for the fastest imaging of large sample areas with the aid of mechanical $\mathrm{XY}$ scanning. Finally, we delineate the possible laser parameter adjustment to further increase the speed of acquisition. With this, we demonstrate that an SHG scan of $1 \mathrm{~cm}^{2}$ of an exemplary mouse skin sample rich in collagen content could be accomplished in under $5 \mathrm{~min}$.

\section{Materials and methods}

\subsection{Wide-field SHG microscope}

The wide-field SHG imaging was performed with a custom-built instrument based on a modular microscope from ASI (Applied Scientific Instruments) (Fig. 1). To collect a larger fraction of the SH signal that is preferentially generated in the direction of laser beam propagation, we exploited the scheme of forward detection: the laser beam was delivered to the sample by an illumination objective Narishige M 10/0.25 210/0 (or Olympus UPlanFL N 40×/0.75), and the resulting $\mathrm{SH}$ signal was collected with a detection objective Olympus PlanC N 10×/0.25. Both objectives were mounted on linear translation stages (LS50, ASI) and the instrument was equipped with a flat-top DC motor stage (S551-2201B, ASI) for the XY sample scanning.

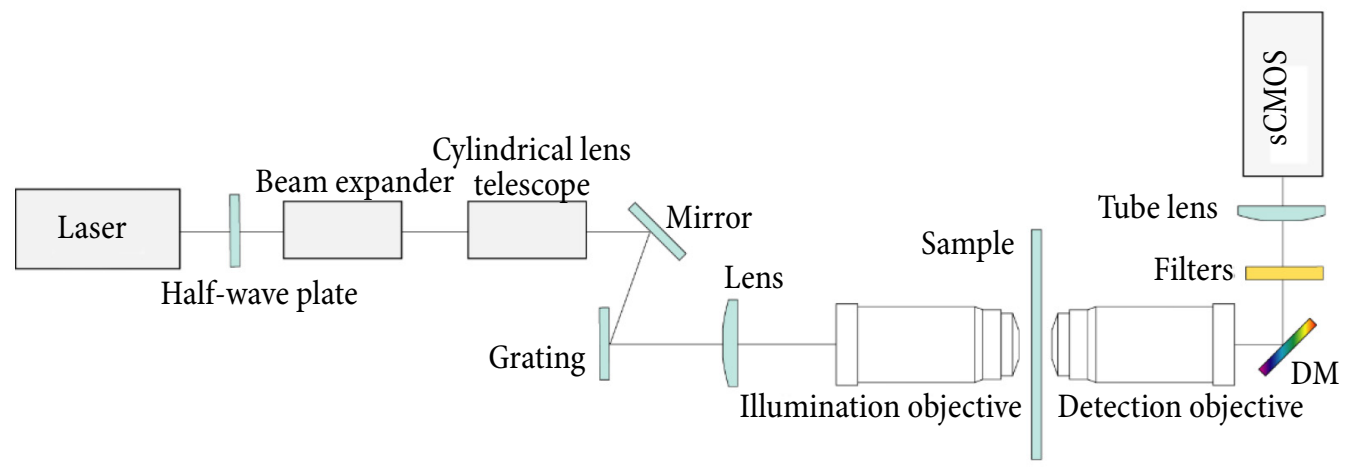

Fig. 1. The principal scheme of the optical setup. 
The laser source was a FemtoLux3 fibre laser from Ekspla. The laser wavelength was $1030 \mathrm{~nm}$. The pulse duration could be adjusted from 262 fs to $4.57 \mathrm{ps}$ and was set to the shortest $262 \mathrm{fs}$. The maximum average laser power was $3 \mathrm{~W}$. The oscillator frequency could be adjusted within $5.44-1 \mathrm{MHz}$ interval corresponding to the pulse energy of $0.55-3 \mu \mathrm{J}$. In our experiments, it was set to the possible maximum of $3 \mu \mathrm{J}$. The pulse repetition frequency could be adjusted with a pulse picker from $10 \mathrm{kHz}-1 \mathrm{MHz}$.

The laser beam could be expanded with an adjustable beam expander (VEX18, Optogama) from 1 to $8 \times$. It was further compressed $2 \times$ along the horizontal direction with a telescope consisting of two cylindrical lenses (LJ1695L1-B and LJ1567L1-B, Thorlabs) to precompensate the ellipticity of the beam cross-section after the reflection from the diffraction grating.

The optical layout contained the simplest scheme of temporal focusing (TF) [12]: the expanded laser beam was diffracted by an 830 grooves $/ \mathrm{mm}$ diffraction grating (46-080, Edmund Optics), and focused by a $250 \mathrm{~mm}$ focal distance achromatic doublet (AC508-250-B, Thorlabs) onto the back focal plane of the illumination objective. The incidence angle was adjusted to $58^{\circ}$ so that the laser beam was diffracted perpendicularly to the plane of the diffraction grating. The distance from the grating to the focusing lens and from the focusing lens to the back focal plane of the objective was adjusted to equal the focal distance of the focusing lens.

The scheme of the temporal focusing was introduced since after the diffraction grating the laser pulse is stretched in duration everywhere along the optical train except for the focal plane of the illumination objective. This then allows the possibility to deliver the full laser power with the maximal pulse energy to the sample without the ensuing damage to the optical elements that could not be avoided with a straightforward wide-field illumination. At the same time, with a low numerical aperture (NA) Narishige objective the full width at half maximum (FWHM) of the profile of the nonlinear excitation efficiency along the optical axis was $810 \mu \mathrm{m}$. The optical sectioning was thus virtually non-existent, but that was inconsequential as in our case the samples were thin tissue sections.

The polarisation of the laser was rotated with the half-wave plate so that the grating diffracted the maximum of the laser light intensity.
After the detection objective, the $\mathrm{SH}$ signal was reflected by a high-pass dichroic mirror (T900LPXXRXT, Chroma) transmitting most of the laser light. The signal was further filtered off the reflected/scattered laser light with a low-pass dielectric filter (ET750SP-2p8, Chroma) and the SH signal was separated with a band-pass dielectric filter (FF01-513/13-25, Semrock). The image was projected with a Nikon tube lens (TN200-MMC, ASI) onto the Andor Neo 5.5 sCMOS detector.

\subsection{Measurement of the TF profile}

The TF profile or the dependence of the efficiency of two-photon absorption on the distance from the focal plane of the illumination objective was measured on a sample of a dyed polymer film by translating the illumination objective relative to the sample, acquiring fluorescence images at different positions, and then calculating the total fluorescence intensity depending on the objective focus-sample distance.

\subsection{Dyed polymer film}

$\sim 300 \mathrm{~nm}$ thick poly(vinyl butyral-co-vinyl alcohol-co-vinyl acetate) (PVB) polymer film doped with low, $0.5 \% \mathrm{wt} / \mathrm{wt}$ concentration of 2-[2-isopropyl-6-[2-(1,1,7,7-tetramethyl-2,3,6,7-tetrahydro- $1 \mathrm{H}, 5 \mathrm{H}$-pyrido[3,2,1-ij]quinoline-9-yl)pyran4-ylidene]-malononitrile (DCM) dye was prepared by spin-coating of $10 \mathrm{mg} / \mathrm{mL}$ PVB (MW 80000) chloroform solution on a glass substrate for $5 \mathrm{~s}$ at $500 \mathrm{rpm}$ and for $30 \mathrm{~s}$ at $1000 \mathrm{rpm}$.

\subsection{Mouse skin samples}

Experiments were performed on female C57BL/6 mice (8-10 weeks, 20-25 g). The mice were kept under standard housing conditions with unlimited food and water access. The mice were maintained in the animal facility of the State Research Institute Centre for Innovative Medicine. The use of animals in this study was in accordance with the Directive 2010/63/EU of the European Parliament and of the Council of 22 September 2010 on the protection of animals used for scientific purposes. The study was approved by the Lithuanian Laboratory Animal Use Ethical Committee under the State Food and Veterinary Service (No G2-113). For the experiment, the dorsal mouse skin of an animal with induced psoriasis-like skin inflammation was used. 
The dorsal skin of mice was shaved using an electric shaver, and the remaining hair were completely removed with depilatory cream one day before the first Aldara (Meda $A B$, Sweden) cream treatment. $62.5 \mathrm{mg}$ of Aldara cream (containing $5 \%$ imiquimod) was applied on the shaved back skin of C57BL/6 mouse on each day of the 6-day experiment [13]. Once the signs of psoriasis were achieved, the mice were sacrificed using cervical dislocation and the treated dorsal skin was collected for further analysis.

Excised dorsal skin tissue samples were formalinfixed (10\%), embedded in paraffin, and $5 \mu \mathrm{m} \mathrm{sec-}$ tions were cut and stained with hematoxylin-eosin (H\&E) according to the standard protocol [14].

\section{Results and discussion}

\subsection{Considerations for the imaging time in the wide- field compared to the laser-scanning}

The number of $\mathrm{SH}$ photons generated per unit time from a unit area can be expressed as

$$
N=k \cdot \chi^{2}\left(\frac{E}{S \cdot \tau}\right)^{2} \tau \cdot f,
$$

where $k$ is the proportionality coefficient, $\chi$ is the second-order effective surface susceptibility, $E$ is the laser pulse energy, $S$ is the illuminated area, $\tau$ is the laser pulse duration, and $f$ is the laser pulse repetition frequency [10, 15.

Then the pixel intensity (in the number of photons) is

$$
B=k \cdot \chi^{2}\left(\frac{E}{S \cdot \tau}\right)^{2} \tau \cdot f \cdot t \cdot S_{\mathrm{p}},
$$

where $t$ is the integration time (of the whole image in the wide-field, and a single pixel with the laserscanning), and $S_{\mathrm{p}}$ is the pixel area.

The integration time required for the acquisition of an image of a certain intensity (number of photons from a pixel) is then

$$
\begin{aligned}
& t=\frac{B}{k \cdot \chi^{2}\left(\frac{E}{S \cdot \tau}\right)^{2} \tau \cdot f \cdot S_{\mathrm{p}}} \\
& =\frac{B \cdot S^{2} \cdot \tau}{k \cdot \chi^{2} \cdot S_{\mathrm{p}}} \frac{1}{P \cdot E}=\frac{B \cdot S^{2} \cdot \tau}{k \cdot \chi^{2} \cdot S_{\mathrm{p}}} \frac{f}{p^{2}},
\end{aligned}
$$

where $P=E \cdot f$ is the average laser power. The image acquisition time in the wide-field simply equals the integration time $T_{\mathrm{wf}}=t_{\mathrm{wp}}$, whereas the image acquisition time with the laser-scanning, disregarding the time overhead associated with the galvanometric mirror inertia, is equal to the pixel integration time times the number of pixels $T_{\mathrm{s}}=t_{\mathrm{s}} \cdot S_{\mathrm{im}} / S_{\mathrm{p}}$, where $S_{\text {im }}$ is the imaged area. For the scanning $S=S_{\mathrm{p}}$, and the wide-field $S=S_{\text {im }}$. Assuming the same pixel size and the same size of the imaged area in the widefield and laser-scanning applications, using Eq. (1) it is straightforward to derive the ratio of the acquisition times of images of the same intensity in the two modes,

$$
\begin{aligned}
& \frac{T_{\mathrm{s}}}{T_{\mathrm{wf}}}=\frac{1}{n} \frac{\tau_{\mathrm{s}}}{\tau_{\mathrm{wf}}}\left(\frac{E_{\mathrm{wf}}}{E_{\mathrm{s}}}\right)^{2} \frac{f_{\mathrm{wf}}}{f_{\mathrm{s}}}=\frac{1}{n} \frac{\tau_{\mathrm{s}}}{\tau_{\mathrm{wf}}}\left(\frac{P_{\mathrm{wf}}}{P_{\mathrm{s}}}\right)^{2} \frac{f_{\mathrm{s}}}{f_{\mathrm{wf}}} \\
& =\frac{1}{n} \frac{\tau_{\mathrm{s}}}{\tau_{\mathrm{wf}}} \frac{P_{\mathrm{wf}}}{P_{\mathrm{s}}} \frac{E_{\mathrm{wf}}}{E_{\mathrm{s}}}=\frac{\tau_{\mathrm{s}}}{\tau_{\mathrm{wf}}} \frac{P_{\mathrm{wf}}}{P_{\mathrm{s}}} \frac{\Phi_{\mathrm{wf}}}{\Phi_{\mathrm{s}}},
\end{aligned}
$$

where s subscript denotes the laser-scanning, wf is the wide-field, $T$ is the image acquisition time, $n=S_{\text {im }} / S_{\mathrm{p}}$ is the number of pixels in an image, and $\Phi=E / S$ is the illumination fluence.

Laser-scanning imaging is normally performed with relatively low pulse energy at high pulse repetition frequency. Typical values are $0.1 \mathrm{~nJ}$ and $90 \mathrm{MHz}$, respectively [16]. In our wide-field setup, we employ a FemtoLux3 laser from Ekspla featuring $3 \mu \mathrm{J}$ of pulse energy at $1 \mathrm{MHz}$ pulse repetition frequency. Assuming for simplicity equal pulse durations, inserting these values together with a typical image size of $512 \times 512$ pixels yields $40 \times$ advantage of the wide-field versus laser-scanning in terms of the speed of image acquisition.

From Eq. (4) it follows that given a certain average laser power in the wide-field, increasing the laser pulse energy increases the ratio of acquisition times with the laser-scanning and in the wide-field. On the other hand, increasing pulse repetition frequency decreases the time ratio. Therefore, having a choice, to shorten the time required for the widefield acquisition, the laser pulse energy should be increased at the expense of the pulse repetition frequency. And the expected advantage of the widefield compared to the laser-scanning in our case is possible due to a relatively high pulse energy of FemtoLux3. At the same time, the excitation fluence (laser pulse energy per unit area), the parameter determining the possible damage to the biological 
material, in this example is lower in the wide-field than in the laser-scanning: for a rough estimate assuming a square pixel of $0.5 \times 0.5 \mu \mathrm{m}^{2}$ in both modes, the fluence in the laser-scanning is $40 \mathrm{~mJ} /$ $\mathrm{cm}^{2}$, whereas in the wide-field it is only $5 \mathrm{~mJ} / \mathrm{cm}^{2}$. The faster image acquisition in the wide-field is possible even with a lower excitation fluence due to the fact that the image is detected effectively with many point detectors in parallel compared to a single point detector in the case of laser-scanning. Thus generating a weaker signal can be compensated by a longer integration time that, however, is still shorter than the image acquisition time with the laser-scanning.

The speed advantage of the wide-field in the limit of excitation fluence being the same as for the laser-scanning, assuming for simplicity equal pulse durations, becomes

$$
\frac{T_{\mathrm{s}}}{T_{\mathrm{wf}}}=\frac{P_{\mathrm{wf}}}{P_{\mathrm{s}}} .
$$

If the pulse energy of FemtoLux 3 were yet 8 times larger, the fluences would be the same in both modes. Then inserting, for illustration, the values of $P_{\mathrm{wf}}=3 \mathrm{~W}$ (the average power of FemtoLux3) and $P_{\mathrm{s}}=10 \mathrm{~mW}$ [16] would yield $T_{\mathrm{s}} / T_{\mathrm{wf}}=300$, which further emphasizes the possible advantage of the wide-field acquisition compared to the laserscanning.

\subsection{Maximal single $S H G$ image size}

Considering the sample area that can be imaged with the available laser parameters, from Eq. (2) it can be expressed as

$$
S=\chi \sqrt{\frac{k \cdot t \cdot S_{\mathrm{p}}}{B \cdot \tau}} \sqrt{E \cdot P}=\chi \sqrt{\frac{k \cdot t \cdot S_{\mathrm{p}}}{B \cdot \tau}} \frac{P}{\sqrt{f}} .
$$

It is obvious that given a certain average power, the size of the $\mathrm{SH}$ image of the desired intensity generated within a chosen integration time is increased by increasing the laser pulse energy, and is decreased by increasing the laser pulse repetition frequency. Therefore, once again, as in the argument of the wide-field advantage over the laserscanning, having a choice, higher laser pulse energy should be favoured over the repetition frequency in order to generate larger $\mathrm{SH}$ images. In the following, we delineate the procedure to experimentally determine the actual image size attainable with the available laser parameters.

We started with a $4 \times$ expanded laser beam, a $250 \mathrm{~mm}$ focal length focusing lens and a $40 \times$ Olympus (4.5 $\mathrm{mm}$ focal distance) illumination objective. With this, the $1 / \mathrm{e}^{2}$ diameter of the fluorescence image of DCM in the polymer film (see Materials and methods) was 148 px. With a 10x Olympus (18 $\mathrm{mm}$ focal distance) detection objective in combination with a $200 \mathrm{~mm}$ focal distance tube lens the image to object transfer coefficient was $1.71 \mathrm{px} / \mu \mathrm{m}$, meaning that we could illuminate a spot with a diameter of $87 \mu \mathrm{m}$. A square fitting into the circle of this diameter would be $105 \mathrm{px} / 61 \mu \mathrm{m}$ large. Next, we performed a scan of $1 \mathrm{~mm}^{2}$ of the mouse skin sample with $10 \mathrm{kHz}$ pulse picker repetition rate ( 0.01 of the maximum average power) and $0.1 \mathrm{~s}$ integration time (data not shown). This particular psoriatic mouse skin preparation (see Materials and methods) was chosen since it contains high collagen concentration and is thus a convenient model sample for the SHG imaging. Following the procedure of the standard fixed tissue sample preparation, it was $\mathrm{H} \& \mathrm{E}$-stained even though the extraneous dyes did not contribute to the SHG signal. The average intensity of $1 \%$ of the most intense pixels in the obtained image was $4.8 \times 10^{3}$. Since the $\mathrm{SH}$ signal intensity is proportional to the pulse repetition frequency, the average intensity with the full laser power $-1 \mathrm{~W}$ at the sample - would be $4.8 \times 10^{5}$. Then, it follows from Eq. (2) that with the same integration time, an image of the arbitrarily chosen average intensity of 1000 (30 dB signal to noise ratio (SNR)) should be possible to acquire from an illuminated area of $\left(4.8 \times 10^{5} / 1000\right)^{1 / 4}=4.7$ times larger size. To illuminate the sample area this large, possible additional expansion of the laser beam (from 4 to 8) would not be sufficient and thus we opted for a smaller, 10× magnification Narishige objective for illumination. Since the Narishige objective was 1.7 times more transmissive to the laser light than the $40 \times$ Olympus objective, the delivered pulse energy was 1.7 times higher and the illuminated area size could be another $1.7^{1 / 2}=1.3$ times larger. In total, an image of 1000 average intensity with $0.1 \mathrm{~s}$ integration time should be possible to obtain from a sample area of 6.1 times larger size than the initial $61 \mu \mathrm{m}$ and equal to $372 \mu \mathrm{m}$. Conversely, with the full laser power through the Narishige 
objective $-1.7 \mathrm{~W}$ at the sample - an image $61 \mu \mathrm{m}$ large and of 1000 average intensity should be possible to record in as little as $0.1 \mathrm{~s} /\left(4.8 \times 10^{5} / 1000\right) / 1$. $72=7.2 \times 10^{-5} \mathrm{~s}$.

\subsection{Imaging of large sample areas}

The ultimate goal of this work was the fastest possible imaging with acceptable signal levels of macroscopic sample areas with microscopic resolution. Sample areas with linear dimensions of tens of millimetres were imaged by mechanical XY scanning and then tiling of the obtained images. The total acquisition time in such a measurement is the sum of the scanning time and the camera integration time that in turn is the product of the number of images and the integration time of a single image. From Eq. (3), if a single image of a chosen intensity of size $x_{1}$ is acquired with the integration time $t_{1}$, an image of the same intensity of size $x_{2}$ can be recorded with the integration time $t_{2}=t_{1}\left(x_{2} / x_{1}\right)^{4}$. Then, the total acquisition time of a tiled image of a chosen intensity, depending on the size of a single image, can be expressed as

$$
T_{\mathrm{t}}=T_{\mathrm{s}}+S_{\mathrm{T}} \frac{x^{2}}{x_{0}^{4}} t_{0},
$$

where $T_{s}$ is the scanning time, $S_{\mathrm{T}}$ is the total tiled image area, $x$ is the size of a single image, and $x_{0}$ is the size of a single image with the integration time $t_{0}$.

The available laser pulse energy can be used to generate SH signal from a relatively large sample area thus yielding a single large image, albeit at the cost of less signal intensity and, as a result, the need for a longer integration time to obtain an image of the desired intensity. A single large image, however, means fewer scanning steps and thus less time required to scan a chosen sample area. Concentrating the laser illumination over a relatively small sample area reverses the ratio of the required integration and scanning times. Therefore, there should exist an optimal single image size resulting in minimum total acquisition time.

To find the conditions for the shortest acquisition time, first, we optimized the scanning speed by setting the XY stage parameters governing its movement to the extreme values: speed $6.5 \mathrm{~mm} / \mathrm{s}$, acceleration within $20 \mathrm{~ms}$, positioning precision $500 \mathrm{~nm}$ (corresponding to about $1 \mathrm{px}$ in an image) and backlash 0 . Then, the scanning time depend- ence $T_{s}(x)$ on the single image size was obtained by scanning an area of $3 \times 3 \mathrm{~mm}^{2}$ at a number of single image sizes, calculating the time required on average to scan $1 \mathrm{~mm}^{2}$, and interpolating the obtained times at intermediate values of the single image size. The resulting curve is shown in Fig. 2(a). For the image of $x_{0}=105 \mathrm{px}$ and 1000 intensity, the $t_{0}=7.2 \times 10^{-5} \mathrm{~s}$ was obtained as explained in the previous section. With this, the total integration time and the total acquisition time depending on the image size were calculated using Eq. (5) and are also shown in Fig. 2(a). It appears that the minimum of the total acquisition time is obtained with the image size from $650-850 \mathrm{px}$ or the corresponding imaged sample area from 380$500 \mu \mathrm{m}$. Thus, the 7 -fold increase of the $105 \mathrm{px}$ image to $735 \mathrm{px}$ (430 $\mu \mathrm{m}$ in the sample), achievable with the $6 \times$ laser beam expansion and the $10 \times$ Narishige objective (focal distance $21 \mathrm{~mm}$ ), would fall into the optimal range. The corresponding required integration time of a single image would be $0.17 \mathrm{~s}$. With these settings, for demonstration, we scanned a $15 \times 5 \mathrm{~mm}^{2}$ area of the mouse skin sample. An example of a single image from a sample area rich with collagen is presented in Fig. 3. The tiled image of the whole scan is presented in Fig. 4. As expected, the average intensity of the image was $\sim 1000$. The total acquisition time was $\sim 200 \mathrm{~s}$. Extrapolating this, $1 \mathrm{~cm}^{2}$ could be imaged in less than $5 \mathrm{~min}$.

Considering the speed of acquisition of a tiled image, the choice of the laser parameters affects $t_{0}$ in Eq. (7). According to Eq. (3), given certain average laser power, if a single image of a chosen intensity is acquired with the integration time $t_{1}$ with the pulse energy $E_{1}$, then with the pulse energy $E_{2}$ an image of the same intensity is recorded within the integration time $t_{2}=t_{1} \cdot E_{1} / E_{2}$. Having this in mind, we calculated the $T_{t}(x)$ dependences for different values of $E$ (Fig. 2(b)): increasing the pulse energy reduces $t_{0}$ thus lowering the parabolic curve of the total integration time, and as a consequence, lowering the value and shifting the position of the minimum of the curve of total acquisition time towards larger values of the image size. Conversely, increasing the pulse repetition frequency at the expense of the pulse energy would increase the $t_{0}$ and thus have the opposite effect on the $T_{t}(x)$ dependence. From these dependences, we built the dependence of the minimum $T_{t}$ on $E$, together with the dependence on $E$ of 

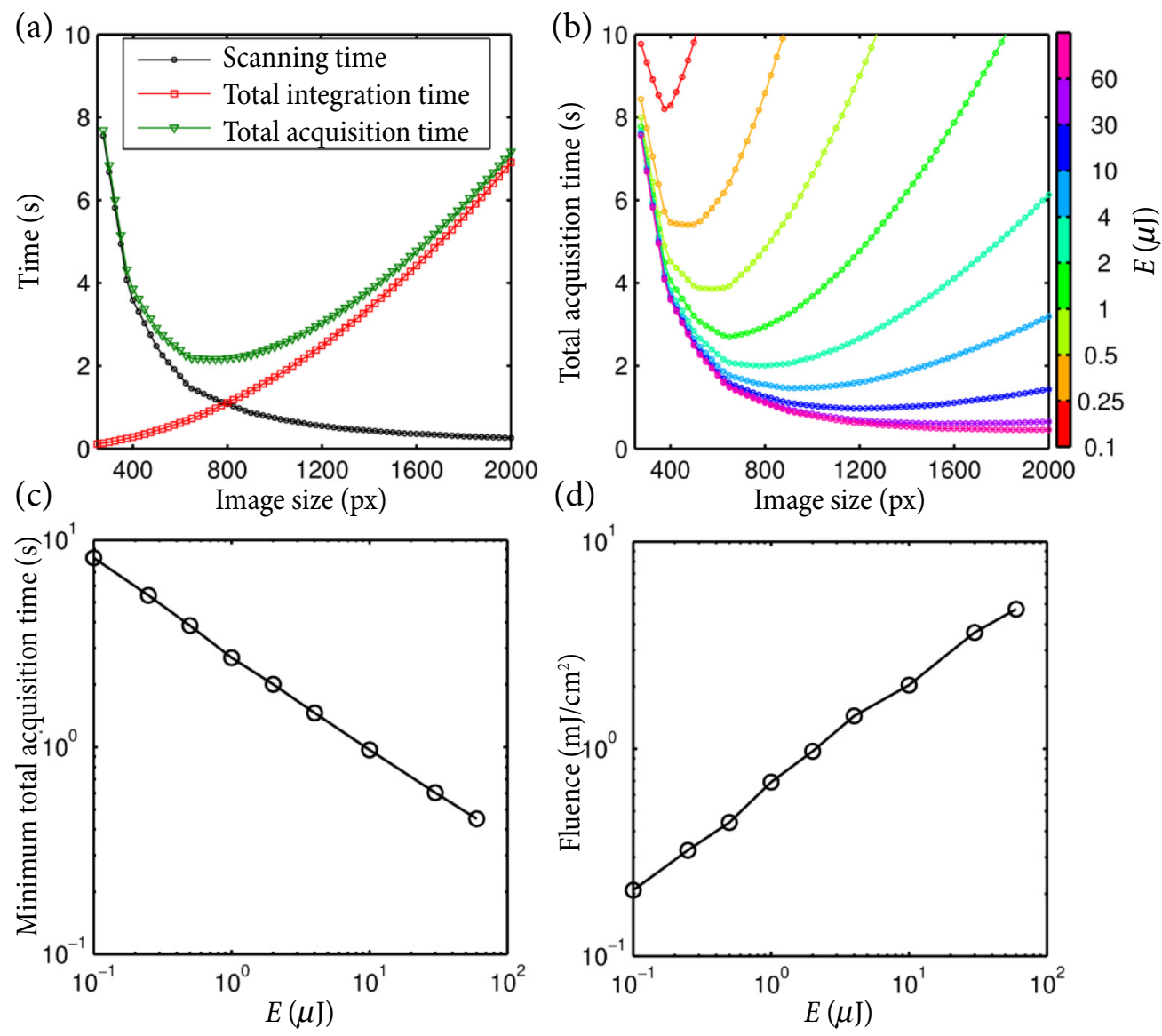

Fig. 2. (a) Dependences on the image size of the scanning time (measured), the total camera integration time (calculated), and the total acquisition time required to acquire an image of 1000 average intensity of an area of $1 \mathrm{~mm}^{2}$; (b) dependences of the total acquisition time on the image size at different values of the laser pulse energy; (c) dependence of the minimum total acquisition time on the laser pulse energy; (d) dependence on the laser pulse energy of the illumination fluence corresponding to the minima of the total acquisition time in (c).

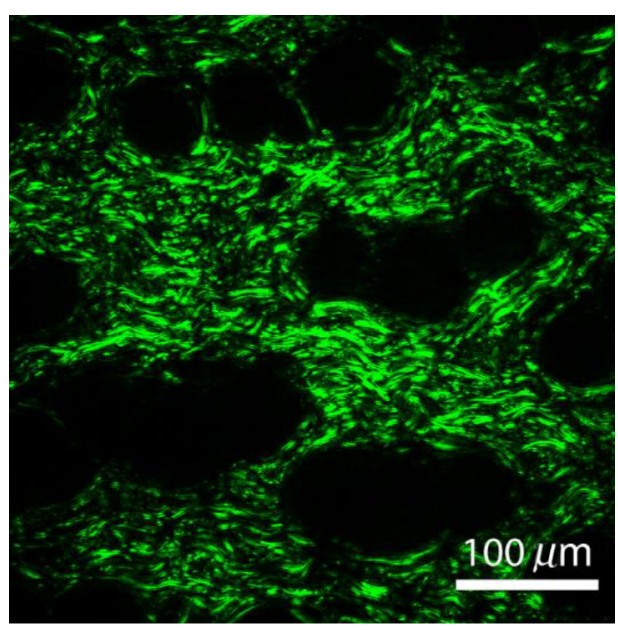

Fig. 3. A single image of $430 \times 430 \mu \mathrm{m}^{2}$ area of a mouse skin sample. The integration time was $0.17 \mathrm{~s}$. The pseudocolour intensity range is $100-500$. the corresponding fluence (Fig. 2(c, d)). The total acquisition time decreases with increasing the laser pulse energy, and this dependence is close to the power dependence with the power coefficient of -0.5 . The opposite is the direction of the dependence on the pulse energy of the illumination fluence. At the same time, with $1.7 \mu \mathrm{J}$ of the pulse energy at the sample in our measurement, the fluence is less than $1 \mathrm{~mJ} / \mathrm{cm}^{2}$, which is well below the known damaging thresholds for different kinds of live cells [17-19] and even more so in the case of the tissue samples, where maintaining the cell vivacity is not an issue. In fact, the mouse skin sample did not exhibit any signs of degradation even with $\sim 50 \times$ higher fluence in the initial measurement for the maximum image size with only a $4 \times$ expanded laser beam and a $40 \times$ magnification illumination 


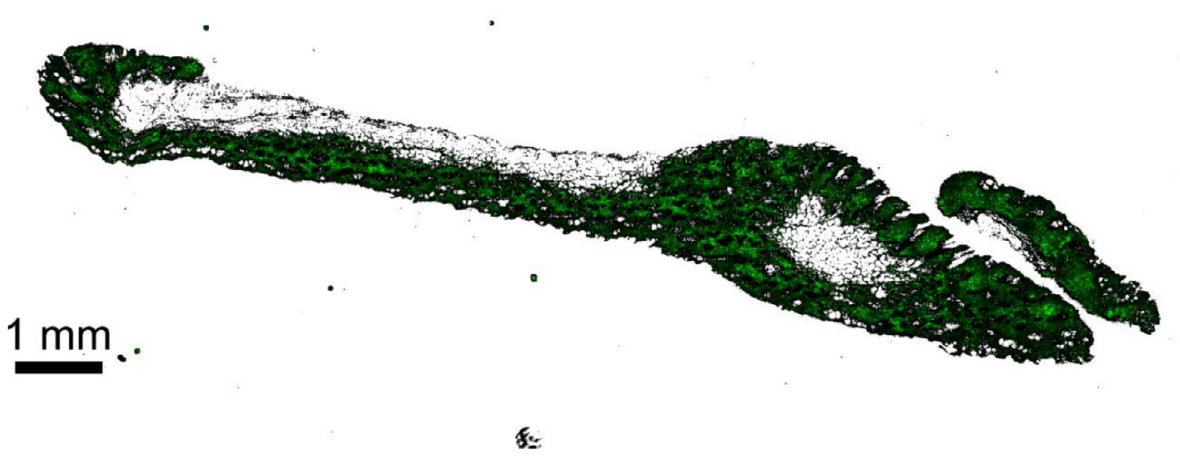

Fig. 4. The tiled image of a $15 \times 5 \mathrm{~mm}^{2}$ scan of a mouse skin sample. The integration time was $0.17 \mathrm{~s}$. The pseudo-colour intensity range is $100-500$.

objective. Therefore, in order to further increase the speed of the tiled image acquisition, the laser pulse energy could be augmented up to a few orders of magnitude higher illumination fluence.

\section{Conclusions}

We have built a wide-field SHG imaging microscope based on a high power, high pulse energy, medium pulse repetition rate laser. We demonstrated that having a choice of the laser parameters, larger single image and faster tiled image acquisition can be achieved by favouring higher laser pulse energy over higher pulse repetition frequency. We proposed quantitative procedures to obtain an image of the desired intensity of the maximum size and to perform a tiled image scan in the least of time. In our setup, we employed a FemtoLux3 laser featuring $3 \mathrm{~W}$ of average power and $3 \mu \mathrm{J}$ of pulse energy. With that and in combination with the mechanical $\mathrm{XY}$ scanning, we were able to acquire a SHG image of $1 \mathrm{~cm}^{2}$ area of a mouse skin sample with $30 \mathrm{~dB}$ SNR in under $5 \mathrm{~min}$.

\section{Funding}

This research was funded by a grant (No. J05-LVPA-K-04-0031) received from the Lithuanian Business Support Agency.

\section{References}

[1] A.P. Franken, A.E. Hill, C.W. Peters, and G. Weinreich, Generation of optical harmonics, Phys. Rev. Lett. 7(1), 118-120 (1961), https://doi. org/10.1103/PhysRevLett.7.118
[2] C.J.R. Sheppard, J.N. Gannaway, R. Kompfner, and D. Walsh, The scanning harmonic optical microscope, IEEE J. Quantum Electron. 13, 912 (1977), https://doi.org/10.1109/JQE.1977.1069615

[3] I. Freund and M. Deutsch, Optical second-harmonic microscopy, crossed-beam summation, and small-angle scattering in rat-tail tendon, Biophys. J. 50(2), 693-712 (1986), https://doi. org/10.1016/S0006-3495(86)83510-X

[4] W. Mohler, A.C. Millard, and P.J. Campagnola, Second harmonic generation imaging of endogenous structural proteins, Methods 29(1), 97-109 (2003), https://doi.org/10.1016/S10462023(02)00292-X

[5] A. Keikhosravi, J.S. Bredfeldt, A.K. Sagar, and K.W. Eliceiri, Second-harmonic generation imaging of cancer, Methods Cell Biol. 123, 531-546 (2014), https://doi.org/10.1016/B978-0-12420138-5.00028-8

[6] P.J. Campagnola and L.M. Loew, Secondharmonic imaging microscopy for visualizing biomolecular arrays in cells, tissues and organisms, Nat. Biotechnol. 21(11), 1356-1360 (2003), https://doi.org/10.1038/nbt894

[7] P.J. Campagnola and C.Y. Dong, Second harmonic generation microscopy: Principles and applications to disease diagnosis, Laser Photonics Rev. 5(1), 13-26 (2011), https://doi.org/10.1002/ Ipor.200910024

[8] J.N. Gannaway and C.J.R. Sheppard, Secondharmonic imaging in the scanning optical microscope, Opt. Quantum Electron. 10, 435-439 (1978), https://doi.org/10.1007/BF00620308 
[9] E.E. Hoover and J.A. Squier, Advances in multiphoton microscopy technology, Nat. Photonics 7, 93-101 (2013), https://doi.org/10.1038/nphoton.2013.361

[10]C. Macias-Romero, M.E.P. Didier, P. Jourdain, P. Marquet, P. Magistretti, O.B. Tarun, V.Zubkovs, A. Radenovic, and S. Roke, High throughput second harmonic imaging for label-free biological applications, Opt. Express 22(25), 31102 (2014), https://doi.org/10.1364/oe.22.031102

[11]H. Zhao, R. Cisek, A. Karunendiran, D. Tokarz, B.A. Stewart, and V. Barzda, Live imaging of contracting muscles with wide-field second harmonic generation microscopy using a high power laser, Biomed. Opt. Express 10(10), 5130 (2019), https://doi.org/10.1364/boe.10.005130

[12]D. Oron, E. Tal, and Y. Silberberg, Scanningless depth-resolved microscopy, Opt. Express 13(5), 1468 (2005), https://doi.org/10.1364 OPEX.13.001468

[13]I.A. Rather, V.K. Bajpai, J.H. Han, and G.J. Nam, Imiquimod-induced psoriasis-like skin inflammation in mouse model, Bangladesh J. Pharmacol. 11(4), 849-851 (2016), https://doi. org/10.3329/bjp.v11i4.28662

[14]R.D. Cardiff, C.H. Miller, and R.J. Munn, Manual hematoxylin and eosin staining of mouse tissue sections, Cold Spring Harb. Protoc. 2014(6),
655-658 (2014), https://doi.org/10.1101/pdb. prot073411

[15]J.I. Dadap, X.F. Hu, N.M. Russell, J.G. Ekerdt, J.K. Lowell, S. Member, and M.C. Downer, Analysis of second-harmonic generation ultrashort laser pulses at $\mathrm{Si}(001)$ interfaces, IEEE J. Sel. Top. Quantum Electron. 1(4), 1145-1155 (1995), https://doi.org/10.1109/2944.488693

[16] R. Cicchi, D. Massi, S. Sestini, P. Carli, V. De Giorgi, T. Lotti, and F.S. Pavone, Multidimensional non-linear laser imaging of Basal Cell Carcinoma, Opt. Express 15(16), 10135 (2007), https://doi. org/10.1364/oe.15.010135

[17]R. Le Harzic, I. Riemann, K. König, C. Wüllner, and C. Donitzky, Influence of femtosecond laser pulse irradiation on the viability of cells at 1035 , 517, and 345 nm, J. Appl. Phys. 102(11), (2007), https://doi.org/10.1063/1.2818107

[18]C. Macias-Romero, V. Zubkovs, S. Wang, and S. Roke, Wide-field medium-repetition-rate multiphoton microscopy reduces photodamage of living cells, Biomed. Opt. Express 7(4), 1458 (2016), https://doi.org/10.1364/boe.7.001458

[19]K. König, P.T.C. So, W.W. Mantulin, and E. Gratton, Cellular response to near-infrared femtosecond laser pulses in two-photon microscopes, Opt. Lett. 22(2), 135 (1997), https://doi. org/10.1364/ol.22.000135

\title{
PLATAUS LAUKO ANTROSIOS HARMONIKOS GENERAVIMO MIKROSKOPO OPTIMIZAVIMAS GREITAM DIDELIŲ BIOLOGINIŲ AUDINIŲ PLOTŲ VAIZDINIMUI
}

\author{
A. Dementjev a, R. Rudys ${ }^{\text {b, c }, ~ R . ~ K a r p i c z ~}{ }^{\text {a }}$, D. Rutkauskas a \\ ${ }^{a}$ Fiziniu ir technologijos mokslu centras, Vilnius, Lietuva \\ ${ }^{\mathrm{b}}$ Inovatyvios medicinos centras, Vilnius, Lietuva \\ ${ }^{c} U A B$ Photosana, Vilnius, Lietuva
}

\section{Santrauka}

Antrosios harmonikos generavimo (AHG) mikroskopija yra papildomų žymių nereikalaujantis vaizdinimo metodas, kurị naudojant įmanoma atvaizduoti detalų kolageno darinių išsidèstymą biologiniuose bandiniuose. Šiame darbe optimizuota makroskopinių fiksuoto audinio bandinių plotų mikroskopinių AHG vaizdu registravimo sparta naudojant plataus lauko vaizdinimą su didelès galios ir vidutinio, $1 \mathrm{MHz}$ impulso pasikartojimo dažnio, lazeriu bei mechaniniu bandinio skenavimu. Skirtingai nei iprastos skenuojančios mikroskopijos atveju, plataus lauko vaizdinimo optimumą lemia apšviečiamo bandinio ploto dydžio ir generuojamo signalo intensyvumo kombinacija. Darbe aprašomos kiekybinès procedūros parenkant vaizdo parametrus maksimaliai sudurtinio vaizdo registravimo spartai. Taip pat apibūdinamas galimas lazerio parametrų optimizavimas siekiant tolesnio tos spartos padinimo. 